\title{
Should we prescribe montelukast to allergic pediatric patients?
}

\author{
Yong Mean Park, MD, PhD \\ Department of Pediatrics, Konkuk University Medical Center, Konkuk University School of Medicine, Seoul, Korea
}

Montelukast, a representative leukotriene receptor antagonist (LTRA), was launched 20 years ago in Korea and, since then, has been used mainly to treat childhood asthma and allergic rhinitis.

Since 2010, LTRA has been prescribed more often than inhaled corticosteroids (ICS) to pediatric asthma patients in Korea. ${ }^{1)}$ Although the efficacy of LTRA is inferior to that of ICS, the effectiveness of LTRA is superior considering patient compliance and medication side effects as demonstrated in several real-world studies. ${ }^{2)}$ With the increasing use of LTRA, the symptoms of pediatric asthma patients are becoming well controlled and their quality of life is improving. ${ }^{2)}$ LTRA is safe, especially in young children, because it has fewer side effects than other asthma medications. Moreover, it rarely causes behavioral changes or ChurgStrauss syndrome. ${ }^{3)}$

Viral wheeze in childhood is well described as an episodic viral wheeze. Although highly controversial, LTRA has proven efficacy for episodic viral wheeze and can be useful when asthma exacerbates by viral infections. ${ }^{4)}$ It is difficult to identify practical biomarkers of LTRA that are safe, easy to take, and effective asthma controllers. To our knowledge, the best LTRA efficacy is seen for treating asthma in young children and asthma of short duration. ${ }^{5)}$ Many recent studies have determined the effectiveness of LTRA treatment by noninvasively measuring eosinophilderived neurotoxin (EDN). EDN may act as a predictor of the development of recurrent wheezing in patients with postrespiratory syncytial virus bronchiolitis. A meta-analysis reported that montelukast reduced EDN levels in children with recurrent wheezing. ${ }^{5)}$ However, most studies of EDN examined patients with recurrent wheezing. Therefore, well-designed studies of EDN in asthma patients remain insufficient, making its application difficult in practical clinical practice.

Now, 20 years after the introduction of montelukast in Korea, this review article ${ }^{6}$ addresses the effects of LTRA on asthma. However, LTRA also has a profound effect on symptom control in children with allergic rhinitis. Of course, as with asthma, LTRA is less effective at treating allergic rhinitis than intranasal steroids, with somewhat contradictory results compared to antihistamines. ${ }^{7)}$ Combination therapy of montelukast and a second- generation antihistamine may be more effective at controlling symptoms than administering monotherapy. ${ }^{8)}$ Intranasal steroid is the primary recommended drug for allergic rhinitis, but for patients who cannot use intranasal steroids, LTRA alone or in combination with an antihistamine may be recommended. ${ }^{9)}$ LTRA is also useful in the presence of asthma and allergic rhinitis and has some effectiveness at alleviating symptoms of allergic conjunctivitis. ${ }^{10)}$

In the absence of key tools for precision medicine, the most appropriate approach for the thoughtful clinician is to perform a therapeutic trial in an individual patient to assess the potential benefit of montelukast. Such a trial should be as objective as possible and finite in length considering the variable natural history of children who wheeze. A significant minority of children can undoubtedly benefit from montelukast, and this approach could be the most effective way to identify such children while minimizing over-prescription to children who do not benefit from this treatment.

\section{Conflicts of interest}

No potential conflict of interest relevant to this article was reported.

See the article "Montelukast use over the past 20 years: monitoring of its effects and safety issues" via https://doi.org/10.3345/ cep.2019.00325.

\section{References}

1. Sol IS, Kim YH, Kim SY, Choi SH, Kim JD, Kim BO, et al. Prescription patterns and burden of pediatric asthma in Korea. Allergy Asthma Immunol Res 2019;11:280-90.

2. Rabe KF, Adachi M, Lai CK, Soriano JB, Vermeire PA, Weiss KB, et al. Worldwide severity and control of asthma in children and adults: the global asthma insights and reality surveys. J Allergy Clin Immunol 2004; 114:40-7.

3. Wechsler ME, Pauwels R, Drazen JM. Leukotriene modifiers and Churg-Strauss syndrome: adverse effect or response to corticosteroid withdrawal? Drug Saf 1999;21:241-51.

Corresponding author: Yong Mean Park, MD, PhD. Department of Pediatrics, Konkuk University Medical Center, Konkuk University School of Medicine, 120-1 Neungdongro, Gwanjingu, Seoul, Korea 
4. Brodlie M, Gupta A, Rodriguez-Martinez CE, Castro-Rodriguez JA, Ducharme FM, McKean MC. Leukotriene receptor antagonists as maintenance and intermittent therapy for episodic viral wheeze in children. Cochrane Database Syst Rev 2015(10):CD008202.

5. Bai J, Xu PR. Montelukast in the treatment of bronchiolitis, a multicenter, randomized, three-blind, placebo-controlled trial. Chin J EvidBased Med 2010:10:1011-5.

6. Lee YJ, Kim CK. Montelukast use over the past 20 years: monitoring of its effects and safety issues. Clin Exp Pediatr 2020;63:376-81.

7. Ratner PH, Howland WC 3rd, Arastu R, Philpot EE, Klein KC, Baidoo $\mathrm{CA}$, et al. Fluticasone propionate aqueous nasal spray provided significantly greater improvement in daytime and nighttime nasal symptoms of seasonal allergic rhinitis compared with montelukast. Ann Allergy Asthma Immunol 2003;90:536-42.
8. Cingi C, Gunhan K, Gage-White L, Unlu H. Efficacy of leukotriene antagonists as concomitant therapy in allergic rhinitis. Laryngoscope 2010; 120:1718-23.

9. Lieberman PL, Settipane RA. Azelastine nasal spray: a review of pharmacology and clinical efficacy in allergic and nonallergic rhinitis. Allergy Asthma Proc 2003;24:95-105.

10. Cingi C, Ozlugedik S. Effects of montelukast on quality of life in patients with persistent allergic rhinitis. Otolaryngol Head Neck Surg 2010;142: 654-8.

How to cite this article: Park YM. Should we prescribe montelukast to allergic pediatric patients? Clin Exp Pediatr 2020;63:389-90. https://doi.org/10.3345/cep.2019.01662 